\begin{tabular}{|c|c|}
\hline Title & Chemoselectivity Control in the A symmetric Hydrogenation of $Y-$ and $\delta$-Keto Esters into Hydroxy Esters or Diols \\
\hline Author(s) & A rai, Noriyoshi; Namba, Takanori; Kawaguchi, Kei; Matsumoto, Y uki; Ohkuma, Takeshi \\
\hline Citation & $\begin{array}{l}\text { A ngewandte Chemie International Edition, 57(5), 1386-1389 } \\
\text { https://doi.org/10.1002/anie.201711363 }\end{array}$ \\
\hline Issue Date & $201801-26$ \\
\hline Doc URL & http://hdl.handle.net/2115/72368 \\
\hline Rights & $\begin{array}{l}\text { This is the peer-reviewed version of the following article: A ngewandte chemie international edition } 57(5) 1386-1389 \\
2018-01-26 \text {, which has been published in final form at https://doi.org/10.1002/anie.201711363. This article may be used } \\
\text { for non-commercial purposes in accordance with Wiley-V CH Terms and Conditions for Self-A rchiving. }\end{array}$ \\
\hline Type & article (author version) \\
\hline File Information & HUSCAP-manuscript-KEto ESter.pdf \\
\hline
\end{tabular}

Instructions for use 


\title{
Chemoselectivity Control in the Asymmetric Hydrogenation of $\gamma$ - and $\delta$-Keto Esters into the Hydroxy Esters or the Diols
}

\author{
Noriyoshi Arai, Takanori Namba, Kei Kawaguchi, Yuki Matsumoto, and Takeshi Ohkuma*
}

\begin{abstract}
Asymmetric hydrogenation of aromatic $\gamma$ - and $\delta$-keto esters into the optically active hydroxy esters or the diols catalyzed by a novel DIPSkewphos/3-AMIQ-Ru(II) complex was studied. Under the optimized conditions (8 atm $\mathrm{H}_{2}$, Ru complex/t- $\mathrm{C}_{4} \mathrm{H}_{9} \mathrm{OK}=$ $1: 3.5,25^{\circ} \mathrm{C}$ ) the $\gamma$ - and $\delta$-hydroxy esters (including $\gamma$-lactones) were obtained in $97 \%-99 \%$ ee quantitatively. When the reaction was conducted under slightly harsh conditions $\left(20 \mathrm{~atm} \mathrm{H}_{2},\left[t-\mathrm{C}_{4} \mathrm{H}_{9} \mathrm{OK}\right]=\right.$ $50 \mathrm{mM}, 40^{\circ} \mathrm{C}$ ), the 1,4- and 1,5-diols were predominantly obtained in $95 \%-99 \%$ ee. The reactivity of the ester group was notably dependent on the length of the carbon-spacer between the two carbonyl moieties of the substrate. The reaction of $\beta$ - and $\varepsilon$-keto esters selectively afforded the hydroxy esters regardless of the reaction conditions. This catalyst system was applied to the enantioselective and ester regio (position)-selective hydrogenation of a $\gamma$ - $\varepsilon$-diketo diester into the tri-hydroxy ester.
\end{abstract}

Enantioselective hydrogenation of keto esters without reduction of the ester groups is an efficient method to produce the corresponding chiral hydroxy esters and lactones. ${ }^{[1]}$ Several well-designed chiral catalysts have been developed and utilized even in industrial-scale reactions. The BINAP-Ru-catalyzed hydrogenation of $\beta$-keto esters developed by Noyori and coworkers is a representative example..$^{[1,2]}$ Asymmetric hydrogenation of keto esters into the chiral diols is also an important transformation. The catalyst should exhibit high enantioselectivity for the reaction of the keto-carbonyl groups, and also should show high activity for the reduction of the less reactive ester moieties. Recently, Zhou and co-workers reported that the Ir complex with a chiral $\mathrm{P}-\mathrm{N}-\mathrm{N}$ tridentate ligand catalyzed asymmetric hydrogenation of $\delta$-aryl- $\delta$-keto esters into the chiral 1,5-diols in excellent enantiomeric excess (ee). ${ }^{[3]}$ The reactivity of the ester group was dependent on the substrate structure, so that the hydrogenation of the $\gamma$-keto ester gave a mixture of the 1,4-diol, the $\gamma$-hydroxy ester, and the $\gamma$ lactone.

We then aimed to develop a novel chiral catalyst that selectively transforms keto esters into either the hydroxy esters or the diols in high enantiomeric purity just by changing the reaction conditions (Scheme 1$)^{[4]}$ Enantiomerically enriched hydroxy esters and diols are both useful synthetic intermediates.

We recently devised $\left[\mathrm{RuX}_{2}\right.$ (diphosphane)(pica)] $(\mathrm{X}=\mathrm{Cl}, \mathrm{Br}$; diphosphane $=$ BINAPs, XyISkewphos; PICA $=\alpha$-picolylamine; see the structure $\mathbf{5 a}$ for example), ${ }^{[5]}$ which efficiently catalyzes asymmetric hydrogenation of sterically congested tert-alkyl ketones, 3-quinuclidinone with a bicyclo[2.2.2] cyclooctane

[*] Prof. Dr. N. Arai, T. Namba, K. Kawaguchi, Y. Matsumoto, Prof. Dr. T. Ohkuma

Division of Applied Chemistry and Frontier Chemistry Center

Faculty of Engineering, Hokkaido University

Sapporo, Hokkaido 060-8628 (Japan)

E-mail: ohkuma@eng.hokudai.ac.jp

Supporting information for this article is given via a link at the end of the document.

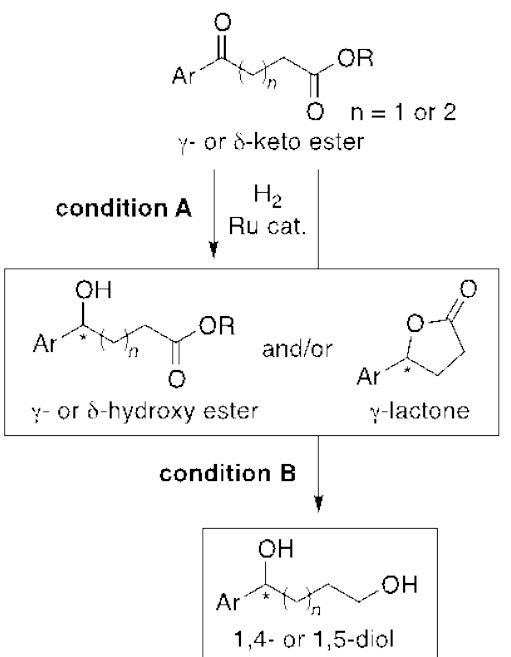

- Chemoselectivity is controlled by changing the reaction conditions.

Scheme 1. Chemo- and enantioselective hydrogenation of $\gamma$ - and $\delta$-keto esters.

skeleton, and acyl silanes in the presence of base. ${ }^{[6,7]}$ The flat shape of the PICA ligand seems to provide a large pocket close to the reaction site for substrates.

We next focused our attention on the electronic properties of the PICA ligands, which have both alkyl amine and pyridine coordinative sites, on the hydrogenation catalysis. Keto esters with two different carbonyl groups were suitable substrates to examine the catalyst efficiency. We here describe asymmetric hydrogenation of aromatic $\gamma$ - and $\delta$-keto esters catalyzed by the novel $\left[\mathrm{RuBr}_{2} \text { (dipskewphos)(3-amiq)] }\right]^{[5]}$ and $t-\mathrm{C}_{4} \mathrm{H}_{9} \mathrm{OK}$ system (Scheme 1). The corresponding $\gamma$ - and $\delta$-hydroxy esters (including $\gamma$-lactones) were obtained in excellent enantiomeric purity under the optimized conditions (condition A). When the reaction was conducted under slightly harsh conditions (condition B), the 1,4- and 1,5-diols in high ee were predominantly obtained.

Hydrogenation of tert-butyl 4-oxo-4-phenylbutanoate (1a; $0.53 \mathrm{mmol})$, an aromatic $\gamma$-keto ester, in ethanol $(1.1 \mathrm{~mL})$ with $\left[\operatorname{RuBr}_{2}\{(\mathrm{~S}, S)\right.$-xylskewphos $\}($ pica $\left.)\right] \quad((S, S)-5 a ; \quad 1.1 \mu \mathrm{mol}$, substrate/catalyst molar ratio $(\mathrm{S} / \mathrm{C})=500: 1)$ and $t-\mathrm{C}_{4} \mathrm{H}_{9} \mathrm{OK}(5.0$ $\mathrm{mM}$ in ethanol, $5.8 \mu \mathrm{mol}$, catalyst/base molar ratio $=1: 5$ ) at $25^{\circ} \mathrm{C}$ under 8 atm of $\mathrm{H}_{2}$ in $2 \mathrm{~h}$ afforded a mixture of tert-butyl 4hydroxy-4-phenylbutanoate (2a, 41\%, 80\% ee), ethyl 4-hydroxy4-phenylbutanoate (2b, 28\%, 77\% ee), 4-phenyl- $\gamma$-butyrolactone (3a, 21\%, 77\% ee), and 1-phenyl-1,4-butanediol (4a, 10\%, 95\% ee) (Table 1, entry 1$).{ }^{[8]}$ The finding that the enantiomeric purity of $\mathbf{4 a}$ was higher than those of $\mathbf{2} \mathbf{a}, \mathbf{2} \mathbf{b}$, and $\mathbf{3} \mathbf{a}$ suggested that partial kinetic resolution occurred through the hydrogenation of ester moieties. Excellent enantiomeric purity of $98 \%$ for the mono-hydrogenated products, $\mathbf{2} \mathbf{a}$ and $\mathbf{2} \mathbf{b}$, was obtained when the sterically more demanding diphosphane ligand DIPSkewphos was coupled with an isoquinoline-PICA analogue 
Table 1. Asymmetric hydrogenation of $\gamma$-keto esters $1 .{ }^{[a]}$<smiles>O=C(O)CCC(=O)c1ccccc1</smiles>

1a: $\mathrm{R}=t-\mathrm{C}_{4} \mathrm{H}_{9}$

1b: $\mathrm{R}=\mathrm{C}_{2} \mathrm{H}_{5}$<smiles>[R]C(=O)CC[C@@H](O)c1ccccc1</smiles>

2a: $\mathrm{R}=t-\mathrm{C}_{4} \mathrm{H}_{9}$ 2b: $\mathrm{R}=\mathrm{C}_{2} \mathrm{H}_{5}$<smiles>O=C1CC[C@@H](c2ccccc2)O1</smiles>

$3 a$<smiles>OCCC[C@@H](O)c1ccccc1</smiles>

$4 a$

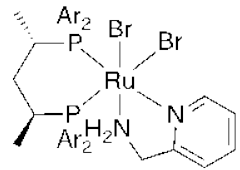

(S,S)-5a: $\mathrm{Ar}=3,5-\left(\mathrm{CH}_{3}\right)_{2} \mathrm{C}_{5} \mathrm{H}_{3}$

\begin{tabular}{|c|c|c|c|c|c|c|c|}
\hline \multirow[b]{2}{*}{ Entry } & \multirow[b]{2}{*}{5} & \multirow[b]{2}{*}{$5 /$ base $^{[b]}$} & \multirow[b]{2}{*}{ [base] $^{[\mathrm{c}]}$} & \multicolumn{4}{|c|}{ Yield $[\%]^{[\mathrm{d}]}$, ee $[\%]^{[\mathrm{e}]}$} \\
\hline & & & & $2 a$ & $2 b$ & $3 a$ & $4 a$ \\
\hline 1 & $5 a$ & $1: 5$ & 5.0 & 41,80 & 28,77 & 21,77 & 10,95 \\
\hline 2 & $5 b$ & $1: 5$ & 5.0 & 79,98 & 6,98 & 11,98 & 4,99 \\
\hline $3^{[f]}$ & $5 b$ & $1: 5$ & 5.0 & - & 40,98 & 54,98 & 6,99 \\
\hline 4 & $5 b$ & $1: 5$ & 2.5 & 89,98 & 2,97 & 8,98 & 1,99 \\
\hline 5 & $5 b$ & $1: 5$ & 1.0 & 85,99 & 2,98 & 11,98 & $<1$, nd \\
\hline 6 & $5 b$ & $1: 3.5$ & 1.0 & $92,{ }^{[9]} 99$ & $<1$, nd & 2,99 & $<1$, nd \\
\hline $7^{[\mathrm{h}]}$ & $5 b$ & $1: 2.5$ & 1.0 & 90,96 & $<1, \mathrm{nd}$ & $<1, \mathrm{nd}$ & $<1$, nd \\
\hline
\end{tabular}

[a] Unless otherwise stated, reactions were conducted at $25^{\circ} \mathrm{C}$ under $8 \mathrm{~atm}$ of $\mathrm{H}_{2}$ for $2 \mathrm{~h}$ using $0.51-0.67 \mathrm{mmol}$ of $\gamma$-keto ester $1 \mathrm{a}$ in ethanol containing $\mathrm{Ru}$ complexes $(S, S)-5$ and $t-\mathrm{C}_{4} \mathrm{H}_{9} \mathrm{OK} .1 \mathrm{a} / \mathbf{5}=500: 1$. Complete conversion of $\mathbf{1 a}$ was observed. [b] $5 / t-\mathrm{C}_{4} \mathrm{H}_{9} \mathrm{OK}$ molar ratio. [c] Concentration of $t-\mathrm{C}_{4} \mathrm{H}_{9} \mathrm{OK}$ $[\mathrm{mM}]$ in the reaction mixture. [d] Determined by ${ }^{1} \mathrm{H}$ NMR analysis. [e] Determined by HPLC analysis on a chiral stationary phase. The ee value of $\mathbf{4 a}$ was determined after conversion to the diacetate. nd: not determined. [f] The ethyl ester 1b was used as a substrate. [g] 92\% isolated yield. [h] $90 \%$ conversion in $24 \mathrm{~h}$.

3-AMIQ on the Ru complex (5b) (entry 2). The yield of the diol 4a was reduced to $4 \%$. The same enantioselectivity was obtained in the reaction of the ethyl ester $\mathbf{1 b}$, although an approximately 1:1.4 mixture of $\mathbf{2} \mathbf{b}$ and $\mathbf{3} \mathbf{a}$ was obtained (entry 3 ). Hydrogenation of the ester moiety was suppressed by decreasing the amount and concentration of base (entries 4-7). Thus, the hydroxy ester $\mathbf{2} \mathbf{a}$ and a small amount of the lactone $\mathbf{3 a}$ both in $99 \%$ ee, were obtained by using 3.5 equivalents of $t$ $\mathrm{C}_{4} \mathrm{H}_{9} \mathrm{OK}(1.0 \mathrm{mM})$ to the complex $5 \mathbf{b}$ (entry 6). No detectable amount of the diol $4 \mathrm{a}$ was obtained under the conditions used. The reaction was not completed even after $24 \mathrm{~h}$ under the less basic conditions $\left(t-\mathrm{C}_{4} \mathrm{H}_{9} \mathrm{OK} / 5 \mathbf{b}=2.5: 1,\left[t-\mathrm{C}_{4} \mathrm{H}_{9} \mathrm{OK}\right]=1.0 \mathrm{mM}\right)$ (entry 7). Notably, no hydrogenation was observed when the $\left[\mathrm{RuCl}_{2}\{(\mathrm{~S})\right.$-binap $\}(\mathrm{S}, S)$-dpen $\left.\}\right]$ and $t-\mathrm{C}_{4} \mathrm{H}_{9} \mathrm{OK}$ system was used as a catalyst. This system is known as a highly active catalyst in the hydrogenation of unfunctionalized ketones. ${ }^{[9]}$

The product composition was dramatically changed by tuning the reaction conditions as shown in Table 2 . Increase of the base concentration and reaction temperature promoted the hydrogenation of the ester moiety. Thus, the hydrogenation of $\gamma$ keto ester $1 \mathbf{a}$ with the Ru complex $5 \mathbf{b}\left(\mathrm{S} / \mathrm{C}=500,8\right.$ atm $\left.\mathrm{H}_{2}\right)$ in ethanol containing $t-\mathrm{C}_{4} \mathrm{H}_{9} \mathrm{OK}(10 \mathrm{mM})$ at $80^{\circ} \mathrm{C}$ in $2 \mathrm{~h}$ afforded the $1,4-$ diol $4 \mathbf{a}$ in $20 \%$ yield and $98 \%$ ee (entry 1 ). The diol $\mathbf{4 a}$ was

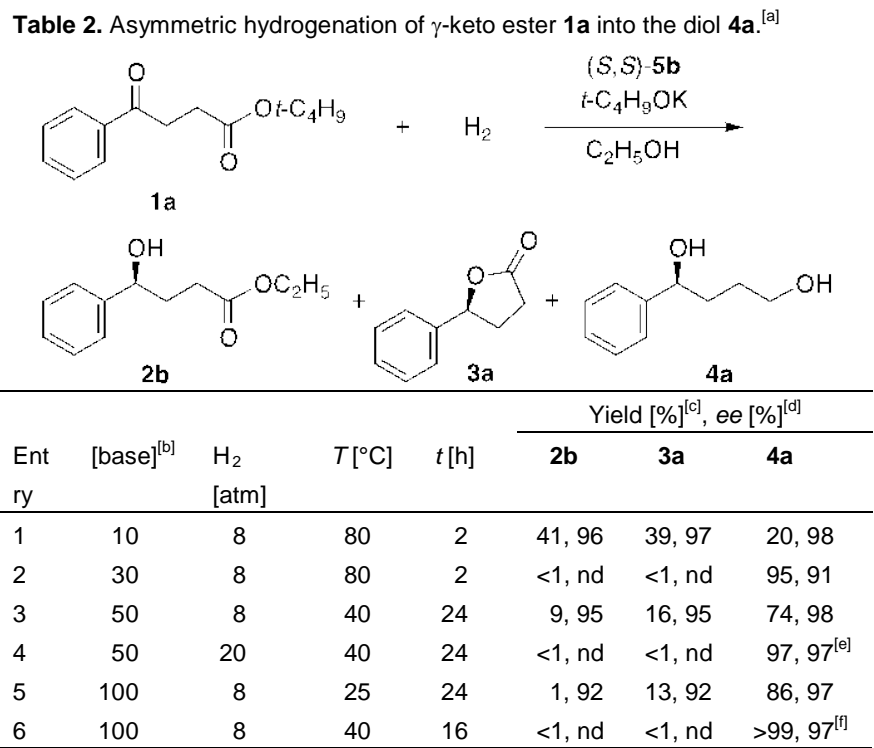

[a] Unless otherwise stated, reactions were conducted using $0.47-0.87 \mathrm{mmo}$ of $\gamma$-keto ester $\mathbf{1 a}$ in ethanol containing Ru complex $(S, S)-5 \mathbf{b}$ and $t-\mathrm{C}_{4} \mathrm{H}_{9} \mathrm{OK}$. $\mathbf{1} \mathbf{a} / \mathbf{5} \mathbf{b}=\mathbf{5 0 0 : 1}$. Complete conversion of $\mathbf{1} \mathbf{a}$ was observed. No tert-butyl ester 2a was detected. [b] Concentration of $t-\mathrm{C}_{4} \mathrm{H}_{9} \mathrm{OK}[\mathrm{mM}]$ in the reaction mixture. [c] Determined by ${ }^{1} \mathrm{H}$ NMR analysis. [d] Determined by HPLC analysis on a chiral stationary phase. The ee value of $\mathbf{4 a}$ was determined after conversion to the diacetate. nd: not determined. [e] 97\% isolated yield, $97.2 \%$ ee. [f] $98 \%$ isolated yield, $96.6 \%$ ee.

obtained as a sole product when the concentration of base was increased to $30 \mathrm{mM}$, but the ee value of $\mathbf{4 a}$ was decreased to $91 \%$ due to racemization of the product and the intermediates (entry 2). As a result of screening of the reaction conditions (entries 3-6), two sets of conditions quantitatively affording the diol $4 \mathrm{a}$ in $97 \%$ ee within $24 \mathrm{~h}$ were found: 1) $50 \mathrm{mM}$ of $t$ $\mathrm{C}_{4} \mathrm{H}_{9} \mathrm{OK}$ at $40^{\circ} \mathrm{C}$ under 20 atm of $\mathrm{H}_{2}$ (entry 4) and 2) $100 \mathrm{mM}$ of $t-\mathrm{C}_{4} \mathrm{H}_{9} \mathrm{OK}$ at $40^{\circ} \mathrm{C}$ under $8 \mathrm{~atm}$ of $\mathrm{H}_{2}$ (entry 6). Thus, the DIPSkewphos/3-AMIQ-Ru(II) catalyst precisely controls chemoselectivity in the hydrogenation of $\gamma$-keto ester $\mathbf{1 a}$, affording either the hydroxy ester $\mathbf{2} \mathbf{a}$ (including the lactone $\mathbf{3 a}$ ) or the 1,4 -diol $\mathbf{4 a}$ in high ee merely by changing the reaction conditions.

We applied the chemo- and enantioselective hydrogenation with the $\mathrm{Ru}$ complex $\mathbf{5 b}$ to a variety of keto ester substrates (Table 3). Two reaction conditions were chosen for these experiments: condition $\mathrm{A}\left(5 \mathrm{~b} / \mathrm{t}-\mathrm{C}_{4} \mathrm{H}_{9} \mathrm{OK}=1: 3.5,8 \mathrm{~atm} \mathrm{H}_{2}, 25^{\circ} \mathrm{C}\right.$ and then lactonization with $t-\mathrm{C}_{4} \mathrm{H}_{9} \mathrm{OK}$ in toluene at $25^{\circ} \mathrm{C}$ when it was necessary), and condition $B\left(\left[t-\mathrm{C}_{4} \mathrm{H}_{9} \mathrm{OK}\right]=50 \mathrm{mM}, 20 \mathrm{~atm}\right.$ $\mathrm{H}_{2}, 40^{\circ} \mathrm{C}$ ). Under condition $\mathrm{A}$, the hydrogenation of aromatic $\gamma-$ keto esters $\mathbf{1 a}, \mathbf{1} \mathbf{c}-\mathbf{1 g}$ with various substitution patterns on the aromatic rings with an S/C of 500 was completed in $2 \mathrm{~h}$, affording the lactones $\mathbf{3 a}, \mathbf{3 c}-\mathbf{3 g}$ in $\mathbf{9 7 - 9 9 \%}$ ee quantitatively after the lactonization (entries 1, 3, and 5-8). No diol products were observed in all cases. The reactions of $1 \mathrm{a}$ and $\mathbf{1 c}$ with an $\mathrm{S} / \mathrm{C}$ of 5000 were completed in $5 \mathrm{~h}$ with maintenance of a high level of enantioselectivity (entries 2 and 4 ).

The $\delta$ - and $\varepsilon$-keto esters $\mathbf{6 a}$ and $\mathbf{6 b}$ were quantitatively converted to the hydroxy esters $\mathbf{7 a}$ and $\mathbf{7 b}$, both in $99 \%$ ee, 
under the typical conditions without the lactonization (entries 9 and 10$){ }^{[10]}$ It is known that $\beta$-keto esters are difficult substrates to hydrogenate with the conventional BINAP/diamine-Ru(II)-type

Table 3. Asymmetric hydrogenation of keto esters into the hydroxy esters or the diols. ${ }^{[a]}$
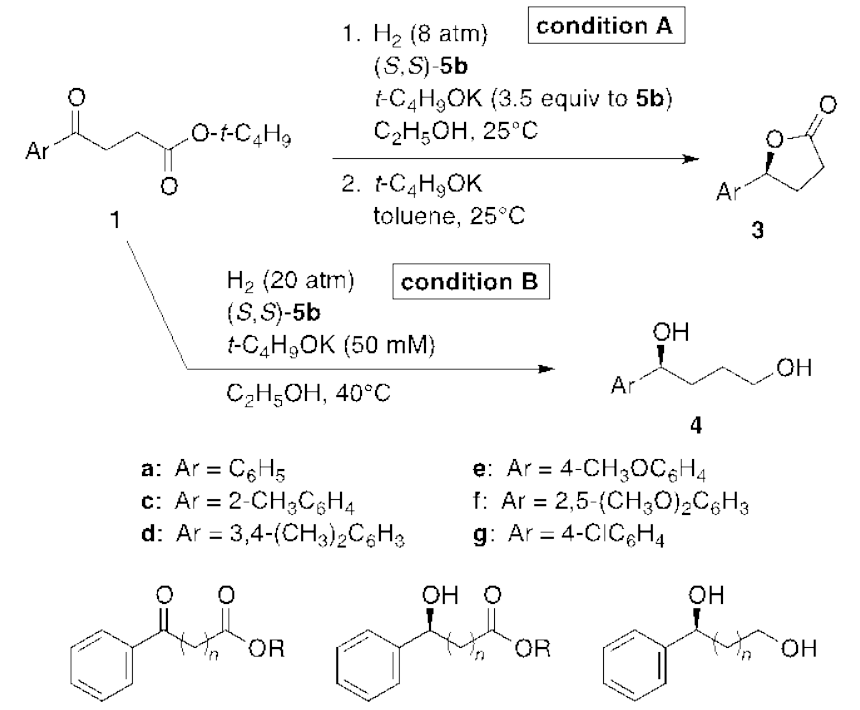

6

7

8

a: $n=3 ; \mathrm{R}=t-\mathrm{C}_{4} \mathrm{H}_{9}$ b: $n=4 ; \mathrm{R}=t-\mathrm{C}_{4} \mathrm{H}_{9} \quad$ c: $n=1 ; \mathrm{R}=\mathrm{C}_{2} \mathrm{H}_{5}$ $[\%]^{[\mathrm{c}]}$, ee $[\%]^{[\mathrm{d}]}$

\begin{tabular}{|c|c|c|c|c|c|}
\hline 1 & A & $1 a$ & 500 & 2 & 3a: $96,99(S)$ \\
\hline 2 & A & $1 a^{[e]}$ & 5000 & 5 & 3a: $97,97(S)$ \\
\hline 3 & A & $1 c$ & 500 & 2 & 3c: $96,99(S)$ \\
\hline 4 & A & $1 c^{[e]}$ & 5000 & 5 & 3c: $97,99(S)$ \\
\hline 5 & A & $1 d$ & 500 & 2 & 3d: 96,99 \\
\hline 6 & A & $1 e$ & 500 & 2 & 3e: $97,99(S)$ \\
\hline 7 & $A$ & 1f & 500 & 2 & 3f: 96,99 \\
\hline 8 & A & $1 g$ & 500 & 2 & 3g: $95,97(S)$ \\
\hline 9 & $A^{[f]}$ & $6 a$ & 500 & 2 & $7 a: 99,99(S)$ \\
\hline 10 & $A^{[f]}$ & $6 b$ & 500 & 2 & 7b: $99,99(S)$ \\
\hline 11 & $A^{[f, h]}$ & $6 c^{[g]}$ & 500 & 24 & 7c: $99,99(S)$ \\
\hline 12 & B & $1 a$ & 500 & 24 & 4a: $97,97(S)$ \\
\hline 13 & $\mathrm{~B}^{[\mathrm{i}]}$ & $1 a^{[e]}$ & 5000 & 40 & 4a: $97,96(S)$ \\
\hline 14 & B & $1 c$ & 500 & 24 & 4c: $95,98(S)$ \\
\hline 15 & $\mathrm{~B}^{[\mathrm{i}]}$ & $1 c^{[e]}$ & 5000 & 40 & 4c: $97,98(S)$ \\
\hline 16 & B & $1 d$ & 500 & 24 & 4d: 96, 97 \\
\hline 17 & B & $1 e$ & 500 & 24 & 4e: $96,97(S)$ \\
\hline 18 & B & $1 f$ & 500 & 24 & 4f: 96,99 \\
\hline 19 & B & $1 \mathrm{~g}$ & 500 & 24 & 4g: $96,95(S)$ \\
\hline 20 & B & $3 a^{[j]}$ & 500 & 24 & 4a: $98,94(S)$ \\
\hline 21 & B & $6 a$ & 500 & 24 & 8a: $96,98(S)$ \\
\hline 22 & B & $6 b$ & 500 & 24 & $7 b: 89,^{[k, 1]} 96(S)$ \\
\hline 23 & B & $6 c$ & 500 & 24 & 7c: $88{ }^{[l, m]}>99(S)$ \\
\hline
\end{tabular}

[a] Unless otherwise stated, reactions were conducted under condition A or B using $0.48-0.78 \mathrm{mmol}$ of keto esters and Ru complex $(S, S)-5 \mathbf{b}$ and $t-\mathrm{C}_{4} \mathrm{H}_{9} \mathrm{OK}$. Complete conversion was observed. [b] Substrate-to-catalyst (5b) molar ratio. [c] Isolated yield of the product. [d] Determined by HPLC analysis on a chiral stationary phase. The ee value of $\mathbf{4 a}$ was determined after conversion to the diacetate. [e] 4.7-5.2 $\mathrm{mmol}$ scale reaction. [f] The cyclization process (condition A, step 2) was not employed. [g] Keto form/enol form = 79:21. [h] Reaction under $20 \mathrm{~atm}$ of $\mathrm{H}_{2}$. [i] Reaction under 50 atm of $\mathrm{H}_{2}$. [j] (S)-3a in
96\% ee was used. [k] 9\% of the ethyl ester was obtained. [l] Diols $\mathbf{8 b}$ and $\mathbf{8 c}$ were not detected. [m] $12 \%$ of ethyl 3-phenyl-2-propenoate was obtained.

catalysts. $^{[9 a]}$ The diamine ligands seemed to be replaced with the strongly chelating substrates on the metal center. Fortunately, this problem was solved by using the Ru complex 5b. A $\beta$-keto ester 6c (keto form/enol form = 79:21) was quantitatively hydrogenated under the modified condition $\mathrm{A}(20$ atm $\mathrm{H}_{2}$ ) to afford the hydroxy ester $7 \mathrm{c}$ in $99 \%$ ee (entry 11 ). ${ }^{[1]}$

When hydrogenation of $\gamma$-keto esters $\mathbf{1 a}, \mathbf{1 c}-\mathbf{1} \mathbf{g}$ with an S/C of 500 was carried out under condition $B$, the diols $\mathbf{4 a}, \mathbf{4 c}-\mathbf{4 g}$ in 95-99\% ee were obtained quantitatively in $24 \mathrm{~h}$ (entries 12, 14, and 16-19). Keto esters $1 \mathbf{a}$ and $\mathbf{1 c}$ were quantitatively converted to the diols under the modified condition B (50 atm of $\mathrm{H}_{2}$ ) at an $\mathrm{S} / \mathrm{C}$ of 5000 in $40 \mathrm{~h}$ without losing the enantioselectivity (entries 13 and 15).

The $\delta$-keto ester $\mathbf{6 a}$ was also predominantly hydrogenated into the 1,5-diol $\mathbf{8 a}$ in $98 \%$ ee under condition B (entry 21). Notably, the $\varepsilon$-keto ester $\mathbf{6 b}$ was converted to the hydroxy ester $\mathbf{7 b}$ in $96 \%$ ee accompanied with the ethyl ester under condition B (entry 22). The hydrogenation of $\beta$-keto esters $6 \mathbf{c}$ also afforded the hydroxy ester 7c as a major product (entry 23). The diol products $\mathbf{8 b}$ and $\mathbf{8 c}$ were not observed in either of these cases. These results suggested that the 1,4- and 1,5-diols 4 and $\mathbf{8 a}$ were obtained through the reduction of reversibly formed $\gamma$ - and $\delta$-lactones. In fact, the $\gamma$-lactone $\mathbf{3 a}$ in $96 \%$ ee was smoothly hydrogenated to the 1,4-diaol $\mathbf{4 a}$ in $94 \%$ ee under condition B (entry 20). ${ }^{[12]}$

We applied the DIPSkewphos/3-AMIQ-Ru(II) catalyst system to the enantioselective and ester regio (position)selective hydrogenation of a $\gamma$ - $\varepsilon$-diketo diester 9 (Scheme 2). The reaction conducted under condition B with an S/C of 250 was completed within $24 \mathrm{~h}$ to afford the tri-hydroxy ester 10 (including $<1 \%$ of the ethyl ester) in $99 \%$ ee with a diastereomeric ratio of 17:1. The relatively low isolated yield of $78 \%$ was due to strong adsorption of the triol $\mathbf{1 0}$ on the $\mathrm{SiO}_{2}$ column. As we expected, no hydrogenation of the ester group at the $\varepsilon$-keto ester moiety was observed, in contrast to complete reduction of the $\gamma$-keto ester moiety.

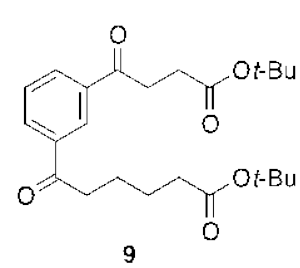

$\mathrm{S} / \mathrm{C}=250$

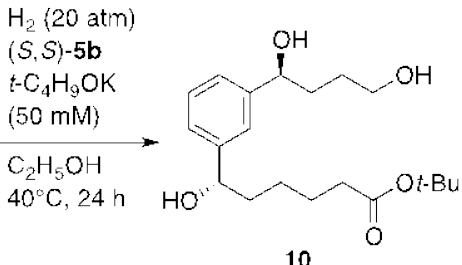

$78 \%$ isolated yield (with $<1 \%$ of the ethyl ester) $99 \%$ ee, dr: 17:1
Scheme 2. Enantioselective and ester regioselective hydrogenation of a $\gamma-\varepsilon$ diketo ester 9 .

In conclusion, we reported herein chemo- and enantioselective hydrogenation of aromatic $\gamma$ - and $\delta$-keto esters with a newly devised DIPSkewphos/3-AMIQ-Ru(II) catalyst 
system. Under the optimized conditions (condition A) the $\gamma$ - and $\delta$-hydroxy esters (including $\gamma$-lactones) were obtained in $97 \%$ $99 \%$ ee quantitatively. On the other hand, the 1,4- and 1,5-diols were predominantly obtained in $95 \%-99 \%$ ee under the slightly harsh conditions (condition $\mathrm{B}$ ). The results were reproducible for the reactions with S/Cs of 500 and 5000 . Thus, the chemoselectivity producing hydroxy esters or diols was precisely controlled just by changing the reaction conditions. The reactivity of the ester group was significantly dependent on the length of the carbon-spacer between the two carbonyl moieties. The reaction of $\beta$ - and $\varepsilon$-keto esters under both conditions selectively afforded the hydroxy esters. The enantioselective and ester regio (position)-selective hydrogenation of a $\gamma$ - $\varepsilon$-diketo diester into the tri-hydroxy ester was also achieved.

\section{Acknowledgements}

We thank Dr. T. Katayama and Mr. N. Utsumi at Kanto Chemical Co., Inc. for useful discussion on production of the DIPSkewphos/3-AMIQ-Ru(II) complex. This work was supported by a Grant-in-Aid from the Japan Society for the Promotion of Science (JSPS) (No. 15H03802) and a grant from the MEXT (Japan) program "Strategic Molecular and Materials Chemistry through Innovative Coupling Reactions" of Hokkaido University.

Keywords: asymmetric catalysis • chemoselectivity • hydrogenation $\bullet$ keto esters $\bullet$ ruthenium

[1] For selected reviews, see: a) T. Ohkuma, R. Noyori in Transition Metals for Organic Synthesis, 2nd ed., Vol. 2 (Eds.: M. Beller, C. Bolm), WileyVCH, Weinheim, 2004, pp 29-113; b) T. Ohkuma, R. Noyori in The Handbook of Homogeneous Hydrogenation, Vol. 3 (Eds.: J. G. de Vries C. J. Elsevier), Wiley-VCH, Weinheim, 2007, pp 1105-1163; c) N. Arai, T. Ohkuma in Science of Synthesis: Stereoselective Synthesis, Vol. 2 (Ed.: G. A. Molander), Thieme, Stuttgart, 2011, pp 9-57; d) T. Ohkuma, N. Arai in Comprehensive Chirality, Vol. 5 (Eds.: E. M. Carreira, H. Yamamoto, K. Maruoka), Elsevier, Amsterdam, 2012, pp 270-300.

[2] a) R. Noyori, T. Ohkuma, M. Kitamura, H. Takaya, N. Sayo, H. Kumobayashi, S. Akutagawa, J. Am. Chem. Soc. 1987, 109, 58565858; b) R. Noyori, Angew. Chem. 2002, 114, 2108-2123; Angew. Chem. Int. Ed. 2002, 41, 2008-2022; Adv. Synth. Catal. 2003, 345, 1532.

[3] X.-H. Yang, J.-H. Xie, W.-P. Liu, Q.-L. Zhou, Angew. Chem. 2013, 125 7987-7990; Angew. Chem. Int. Ed. 2013, 52, 7833-7836. For kinetic resolution of $\delta$-hydroxy esters by asymmetric hydrogenation, see: X.-H. Yang, K. Wang, S.-F. Zhu, J.-H. Xie, Q.-L. Zhou, J. Am. Chem. Soc. 2014, 136, 17426-17429.
[4] For achiral hydrogenation of $\alpha$-keto esters into the $\alpha$-hydroxy esters or the 1,2-diols, see: S. Gao, W. Tang, M. Zhang, C. Wang, J. Xiao Synlett 2016, 27, 1748-1752.

[5] 3 -AMIQ = 3-aminomethylisoquinoline. BINAP = 2,2' bis(diphenylphosphanyl)-1,1'-binaphthyl. DIPSkewphos $=2,4$-bis[(3,5diisopropyl)phenylphosphanyl]pentane. XylSkewphos $=2,4$-bis $(3,5$ xylylphosphanyl)pentane.

[6] a) T. Ohkuma, C. A. Sandoval, R. Srinivasan, Q. Lin, Y. Wei, K. Muñiz, R. Noyori, J. Am. Chem. Soc. 2005, 127, 8288-8289; b) N. Arai, K. Suzuki, S. Sugizaki, H. Sorimachi, T. Ohkuma, Angew. Chem. 2008 120, 1794-1797; Angew. Chem. Int. Ed. 2008, 47, 1770-1773; c) K. Tsutsumi, T. Katayama, N. Utsumi, K. Murata, N. Arai, N. Kurono, T. Ohkuma, Org. Process Res. Dev. 2009, 13, 625-628; d) T. Ohkuma, N. Arai, Chem. Rec. 2016, 16, 2801-2819.

[7] For transfer hydrogenation of ketones by using $\left[\mathrm{RuCl}_{2}\right.$ (diphosphane)(pica)], see: W. Baratta, E. Herdtweck, K. Siega, M. Toniutti, P. Rigo, Organometallics 2005, 24, 1660-1669.

[8] For asymmetric hydrogenation of ethyl 4-oxo-4-phenylbutanoate into the hydroxy esters catalyzed by BINAP-Ru(II) complexes, see: a) T. Ohkuma, M. Kitamura, R. Noyori, Tetrahedron Lett. 1990, 31, 5509$5512\left(\left[\mathrm{Ru}\left(\mathrm{OCOCH}_{3}\right)_{2}\right.\right.$ (binap) $]-\mathrm{HCl}, \mathrm{S} / \mathrm{C}=333,100 \mathrm{~atm} \mathrm{H}_{2}, 35^{\circ} \mathrm{C}, 258$ h, $30 \%$ yield, $97 \%$ ee); b) E. V. Starodubtseva, O. V. Turova, M. G Vinogradov, L. S. Gorshkova, V. A. Ferapontov, M. I. Struchkova Tetrahedron 2008, 64, 11713-11717 ([RuCl 3$]-\mathrm{BINAP}-\mathrm{HCl}, \mathrm{S} / \mathrm{C}=500$, 60 atm $\mathrm{H}_{2}, 60^{\circ} \mathrm{C}, 65 \mathrm{~h}, 65 \%$ yield, $91 \%$ ee)

[9] a) T. Ohkuma, H. Ooka, S. Hashiguchi, T. Ikariya, R. Noyori, J. Am Chem. Soc. 1995, 117, 2675-2676; b) H. Doucet, T. Ohkuma, K Murata, T. Yokozawa, M. Kozawa, E. Katayama, A. F. England, T. Ikariya, R. Noyori, Angew. Chem. 1998, 110, 1792-1796; Angew. Chem. Int. Ed. 1998, 37, 1703-1707; c) R. Noyori, T. Ohkuma, Angew. Chem. 2001, 113, 40-75; Angew. Chem. Int. Ed. 2001, 40, 40-73. DPEN = 1,2-diphenylethylenediamine.

[10] For asymmetric hydrogenation of $\delta$ - and $\varepsilon$-keto esters into the hydroxy esters, see: a) B. S. Lucas, B. Fisher, L. R. McGee, S. H. Olson, J. C. Medina, E. Cheung, J. Am. Chem. Soc. 2012, 134, 12855-12860; b) S Rodrígues, B. Qu, K. R. Fandrick, F. Buono, N, Haddad, Y. Xu, M. A Herbage, X. Zeng, S. Ma, N. Grinberg, H. Lee, Z. S. Han, N. K. Yee, C. H. Senanayake, Adv. Synth. Catal. 2014, 356, 301-307; c) G.-L. Zhu X.-D. Zhang, L.-J. Yang, J.-H. Xie, D.-Q. Che, Q. L. Zhou, P.-C. Yan, Y.-Q. Li, Org. Process Res. Dev. 2016, 20, 81-85.

[11] For hydrogenation of $\beta$-aryl- $\beta$-keto esters with excellent enantioselectivity, see for example: a) Y.-G. Zhou, W. Tang, W.-B. Wang, W. Li, X. Zhang, J. Am. Chem. Soc. 2002, 124, 4952-4953; b) A. Hu, H. L. Ngo, W. Lin, Angew. Chem. 2004, 116, 2555-2558; Angew. Chem. Int. Ed. 2004, 43, 2501-2504; c) T. Imamoto, M. Nishimura, A Koide, K. Yoshida, J. Org. Chem. 2007, 72, 7413-7416; d) X. Sun, W. Li, G. Hou, L. Zhou, X. Zhang, Adv. Synth. Catal. 2009, 351, 25532557; e) J.-H. Xie, X.-Y. Liu, X.-H. Yang, J.-B. Xie, L.-X. Wang, Q.-L. Zhou, Angew. Chem. 2012, 124, 205-207; Angew. Chem. Int. Ed. 2012, 51, 201-203.

[12] For achiral hydrogenation of $\delta$-lactones with the BINAP/DPEN-Ru(II) catalyst, see: S. Takebayashi, S. H. Bergens, Organometallics 2009, 28 , 2349-2351. 
Entry for the Table of Contents (Please choose one layout)

Layout 2:

\section{COMMUNICATION}

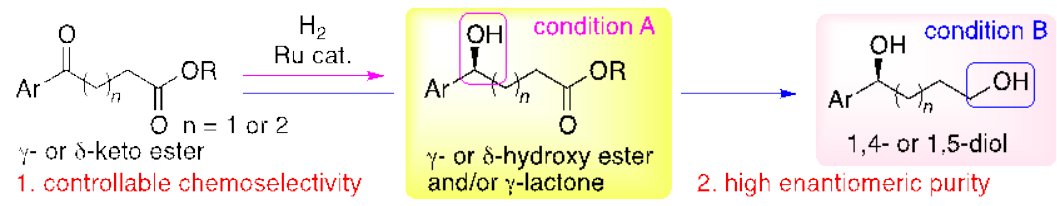

Chemoselectivity in the asymmetric hydrogenation of $\gamma$ - and $\delta$-keto esters into the hydroxy esters (including the lactones) or the diols catalyzed by the novel DIPSkewphos/3-AMIQ-Ru(II) complex was precisely controlled just by changing the reaction conditions. The enantiomeric purity of both products was very high $(95 \%-99 \%$ ee). The $\beta$ - and $\varepsilon$-keto esters were selectively converted to the hydroxy esters regardless of the reaction conditions.
Noriyoshi Arai, Takanori Namba, Kei Kawaguchi, Yuki Matsumoto, and Takeshi Ohkuma*

Page No. - Page No.

Chemoselectivity Control in the Asymmetric Hydrogenation of $\gamma$ - and $\delta$-Keto Esters into the Hydroxy Esters or the Diols 